\title{
COMENTARIO FINAL
}

La gran complejidad del cáncer de recto, debida a la infinidad de variables que influyen en los resultados del tratamiento, la creciente cantidad de estrategias diagnósticas y terapéuticas disponibles, y la abrumadora información producto de una cada vez más profusa bibliografía, hacen que esta enfermedad deba considerarse como una superespecialidad. Es decir, una subespecialidad de cada una de las especialidades implicadas en todas las instancias de decisión, cuyos actores de manera impres- cindible deben definir sus conductas con un enfoque interdisciplinario y en el contexto de un EID. Más allá de la existencia de recomendaciones generales, todas las decisiones deben ser discutidas en ese ámbito, y adaptadas a cada caso en particular.

Este Relato ha intentado establecer ideales de atención, pero las decisiones que se tomen ante cada caso deben adaptarse al nivel de especialización del equipo tratante y a los medios disponibles. 